$15^{\text {th }}$ International Conference on

AEROSPACE SCIENCES \& AVIATION TECHNOLOGY,

$\boldsymbol{A S A T}$ - 15 - May 28 - 30, 2013, Email: asat@mtc.edu.eg, Military Technical College, Kobry Elkobbah, Cairo, Egypt, Tel: +(202) 24025292 -24036138, Fax: +(202) 22621908

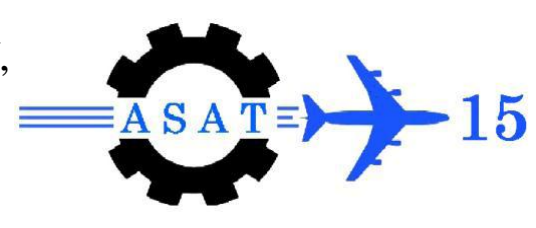

\title{
Experimental Study of the Effect of Blade Configurations on the Performance of Centrifugal Pumps
}

\author{
A. Sadek ${ }^{*}$, I. Saleh ${ }^{*}$, R. Nassif ${ }^{\dagger}$, E. Mouris ${ }^{\dagger}$
}

\begin{abstract}
In the present paper, the effect of change the blade configurations of the centrifugal pump impeller on its performance has been investigated. The pump under investigation has been designed and manufactured to be able to change its blades configurations in a way that the performance of the pump could be measured. The blades configurations have been tested for conventional blades, as well as split to two and three parts. The split blades were tested for clockwise and anti-clock-wise shifting.
\end{abstract}

The experimental test rig has been carried out and the pump performances, (speed- head- flow rate- power and efficiency) have been measured for conventional impeller blades configuration, as well as for eight iterations of different impeller configurations according to the blades arrangement for different rotational speed ranged from 700 to $1450 \mathrm{rpm}$. The main blade configuration parameters are the splitting angle (forward or backward) and splitting diameter.

The results showed that, for the same pump rotational speed, the pump head, efficiency and design flow rate, may increase or decrease by 12 to $16 \%$, compared to the basic impeller configuration.

\section{1- Introduction}

Centrifugal pumps are widely used because of their design simplicity, high efficiency, wide range of capacity, head, smooth flow rate, and ease of operation and maintenance. The development of centrifugal pumps was very rapid due to its relatively inexpensive manufacturing and its ability to handle voluminous amounts of fluid.

The blade number of the impeller and their configurations are considered as important design parameters in centrifugal pumps design. They may affect the pump performance in a way that the existence of the back flow and flow separation in the vane passage which may lead to pressure fluctuations and efficiency drop. The pressure coefficient increases when the splitter is placed closer to the suction side of the main blade. Increasing the length of the splitter can raise the pressure coefficient with little or no effect on efficiency [1]. The outlet velocity profile is improved by splitting vanes; relative velocity increases evidently with the increase of flow rate [2]. The complex internal flow patterns were acquired and the relative velocity varying law near the suction surfaces and pressure surfaces of long blades and the operation sides and opposite sides of short blades were also revealed[3]. The suction performance was

\footnotetext{
Egyptian Armed Forces, Egypt.

Ain Shams University, Egypt.
} 
improved mainly at partial flow rates if the leading edges of splitter blades were located at $20 \%$ of the meridional chord length and improved mainly at larger flow rates if the leading edges of splitter blades were located at $40 \%$ of the meridional chord length [4]. The head of the backward centrifugal pump (specific speed $=63.61$ ) has been increased by $5 \%$ to $18 \%$ when slotted vanes are used with width to blade length is from $18 \%$ to $22 \%$, and the ratio between the slot position and blade length is from 35\% to 50\% [5]. With increasing the cut piece of blade edge the pump head exceeded the original head [6]. The back flow in the impeller has an important influence on the performance of pump and a more-blade complex impeller with long, mid and short blades can effectively solve low flow rate instability of the low-specific-speed centrifugal pump [7]. The experimental findings showed that the high vibrations at the blade-passing frequency are primarily raised by high pressure pulsation due to improper gap design [8]. Adding splitters had a positive effect on the pressure fluctuations which decreased at the casing duct [9]. The most remarkable result is that the optimized geometry has an advantage in the amplitude of pressure pulsation reducing considerably the amplitudes in the outlet pipe [10].

In the present paper, as an exploring work to enhance the centrifugal pump performance, the effect of changing the blade configuration from conventional curved blade to a new blade arrangement with splitters have been highlighted. This arrangement will be compared with the conventional one to study their effects on the pump performance.

\section{Experimental Test Rig}

Experimental work is usually necessary as a bench mark for investigating the flow field in centrifugal pumps as well as a tool for the verification of the theoretical study. In the present study, an experimental test rig has been carried out to investigate the effect of new splitter / blades configurations in centrifugal pump impeller, either adding splitters in curved or staggered arrangements, on the centrifugal pump performance. The test rig has been commissioned at the hydraulic lab in the Department of Mechanical Power in the Faculty of Engineering at Ain Shams University.

A schematic drawing of the experimental test rig arrangement has been introduced in Figure 1. The experimental test rig consists of, a centrifugal pump of designed flow rate of $0.015 \mathrm{~m}^{3} / \mathrm{s}$ and head of $21 \mathrm{~m}$ running at $1450 \mathrm{rpm}$ derived by an electric motor of $10 \mathrm{HP}$ (7.5 $\mathrm{KW})$. The pump impeller of radial type has 5 backward blades with outer diameter of $0.28 \mathrm{~m}$ and $0.1 \mathrm{~m}$ eye diameter. The pump is supplied from a tank of $5 \mathrm{~m}^{3}$ capacity and the pipeline has a control delivery valve. The pump is driven by means of a variable speed electric motor with a controller allows the pump speed to vary from zero to $1450 \mathrm{rpm}$.

\subsection{Different Impeller Configurations}

The centrifugal pump has been manufactured with five blades. The modified pump impeller is designed and manufactured to fit a pump in the hydraulic laboratory. The original impeller configuration with its principal dimensions has been shown in Figure 2, where the blades have their own curved flow path. Impeller configuration has been modified to introduce staggered arrangement with different iterations as shown in Figures 3.

Every blade divided into three equal parts so that each part can be fixed separately and the shroud divided into 15 parts (at angle $24^{\circ}$ ) to give an opportunity to change the blade configuration into four stages. Table 1 shows the staggered angle of the impeller blade parts. 


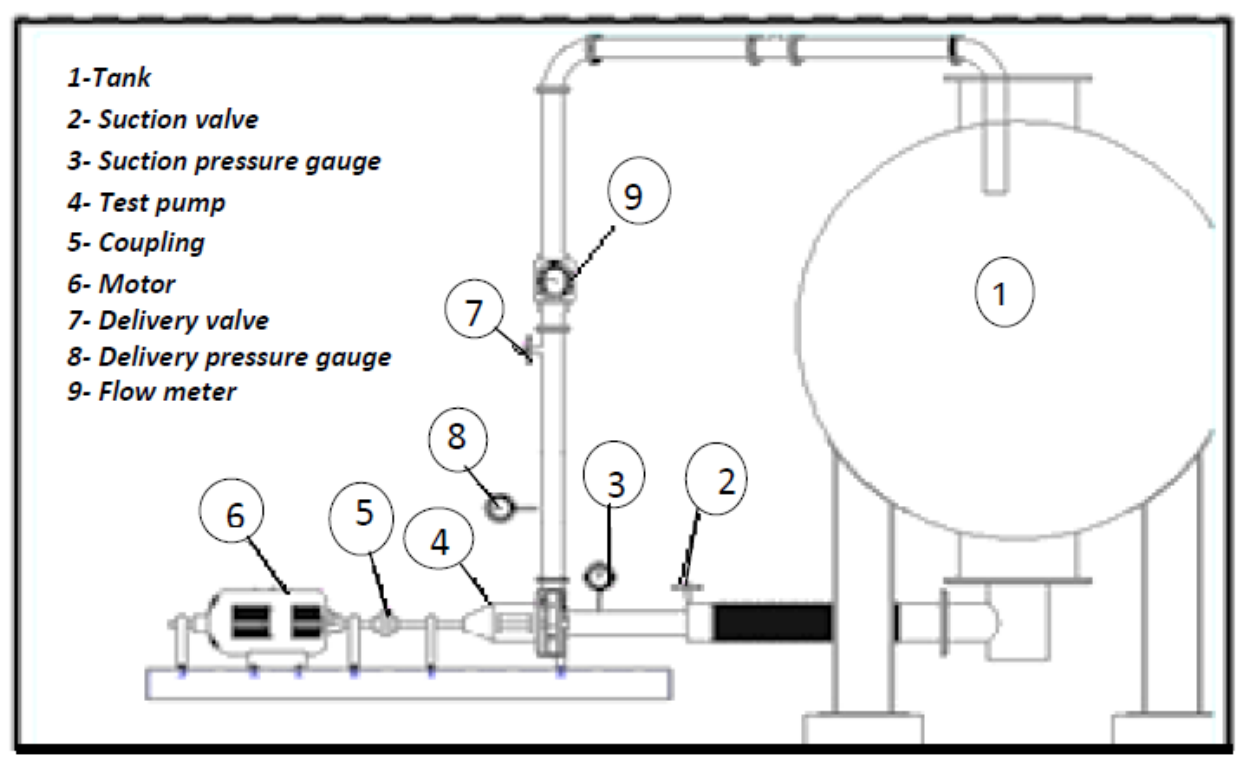

Fig. 1: Schematic diagram of the Experimental test rig arrangement

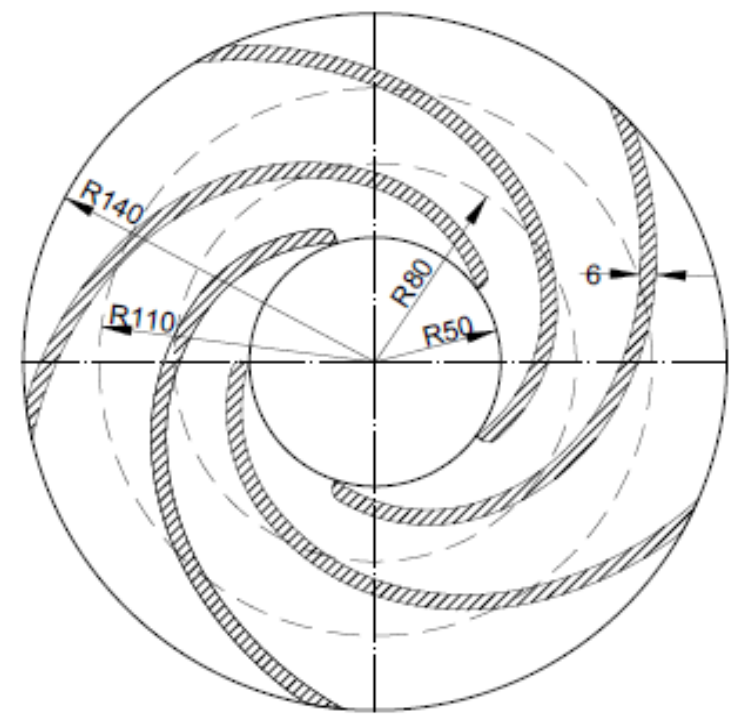

Fig. 2: Original impeller configuration. 


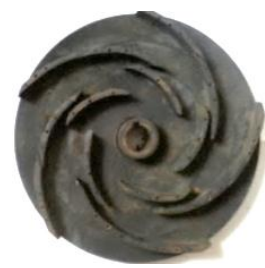

First and Second iterations

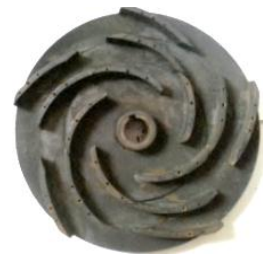

Fifth and Sixth Iterations
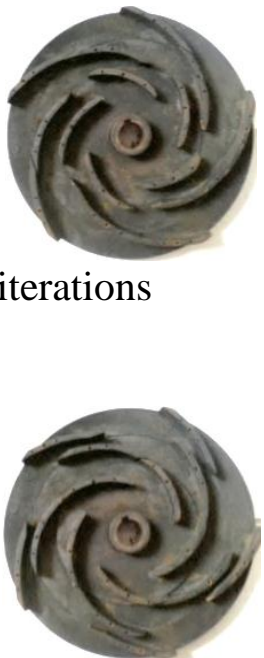

Fig. 3 Modified Blades of the Impeller

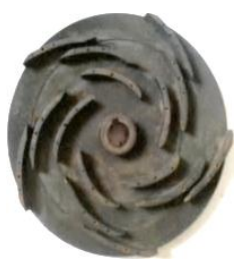

Third and fourth Iterations
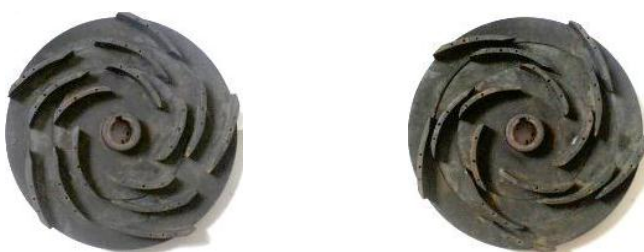

Seventh and Eighth Iterations

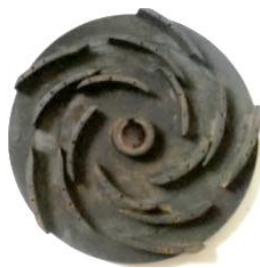

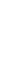




$$
H_{p}=\frac{P_{d}-P_{s}}{\rho_{g}}+\frac{v_{d}^{2}-v_{s}^{2}}{2 g}
$$

where $H_{p}$ is the pumps head in meters, $P_{s}$ and $P_{d}$ are the pump suction and discharge in $\mathrm{Pa}, \rho$ is the water density $10^{3} \mathrm{~kg} / \mathrm{m}^{3}$. The pump driving motor revolution is controlled for keeping its revolution constant and the flow rate is controlled via a delivery flow valve. Discharge can be increased or decreased as desired for a set of different discharges.

The measurements have been carried out at different working pump speeds of $700 \mathrm{rpm}, 900$ $\mathrm{rpm}, 1200 \mathrm{rpm}$, and $1450 \mathrm{rpm}$ respectively. The experimental results have been measured for constant rpm and due to the slip factor in the running; some measured have been actually deviated from the required value. In order to produce the pump flow rate, head and power at constant rpm, there points have been moved to the required rpm by using similarity groups as follows:

$$
\begin{aligned}
& \frac{Q_{1}}{Q_{2}}=\frac{n_{1}}{n_{2}} \\
& \frac{H_{1}}{H_{2}}=\frac{n_{1}^{2}}{n_{2}^{2}} \\
& \frac{N_{1}}{N_{2}}=\frac{n_{1}^{2}}{n_{2}^{2}}
\end{aligned}
$$

Nine sets of experiments have been carried out for normal impeller and variable blades configuration.

\section{Experimental Results}

The experimental results had been measured for different blades configuration at various impeller rotational speed of $700 \mathrm{rpm}, \mathrm{n}=900 \mathrm{rpm}, \mathrm{n}=1200 \mathrm{rpm}$, and $\mathrm{n}=1450 \mathrm{rpm}$. The experimental results have been classified into groups to show the effect of different configurations of the impeller blades on the pump performance at constant rotational speed of $1450 \mathrm{rpm}$. Then the effects of changing pump speeds with different configurations of the impeller blades on the pump performance have been investigated.

\subsection{Effect of Different Impeller Configurations on the Pump Performance at Constant Pump Speed}

The experimental results of the effect of different impeller configurations on the pump performance at constant rotational speed $(n=1450 \mathrm{rpm})$ have been showed in Figures 4, 5 .

For $1^{\text {st }}$ stage, the head for conventional impeller is higher than the head for $1^{\text {st }}$ iteration and $2^{\text {nd }}$ iteration and the head for $1^{\text {st }}$ iteration is higher than the head for $2^{\text {nd }}$ iteration, the pump efficiency for conventional impeller is better than the efficiency for $1^{\text {st }}$ iteration and $2^{\text {nd }}$ iteration, this result is in good agreement with that predicted in, [4], [9], the efficiency for $1^{\text {st }}$ iteration is higher than the efficiency for $2^{\text {nd }}$ iteration. This means that the pump head and efficiency are not improved with changing the middle and outer parts of the blade configuration, but rotating these parts clockwise have better effect than rotating counter clockwise. 


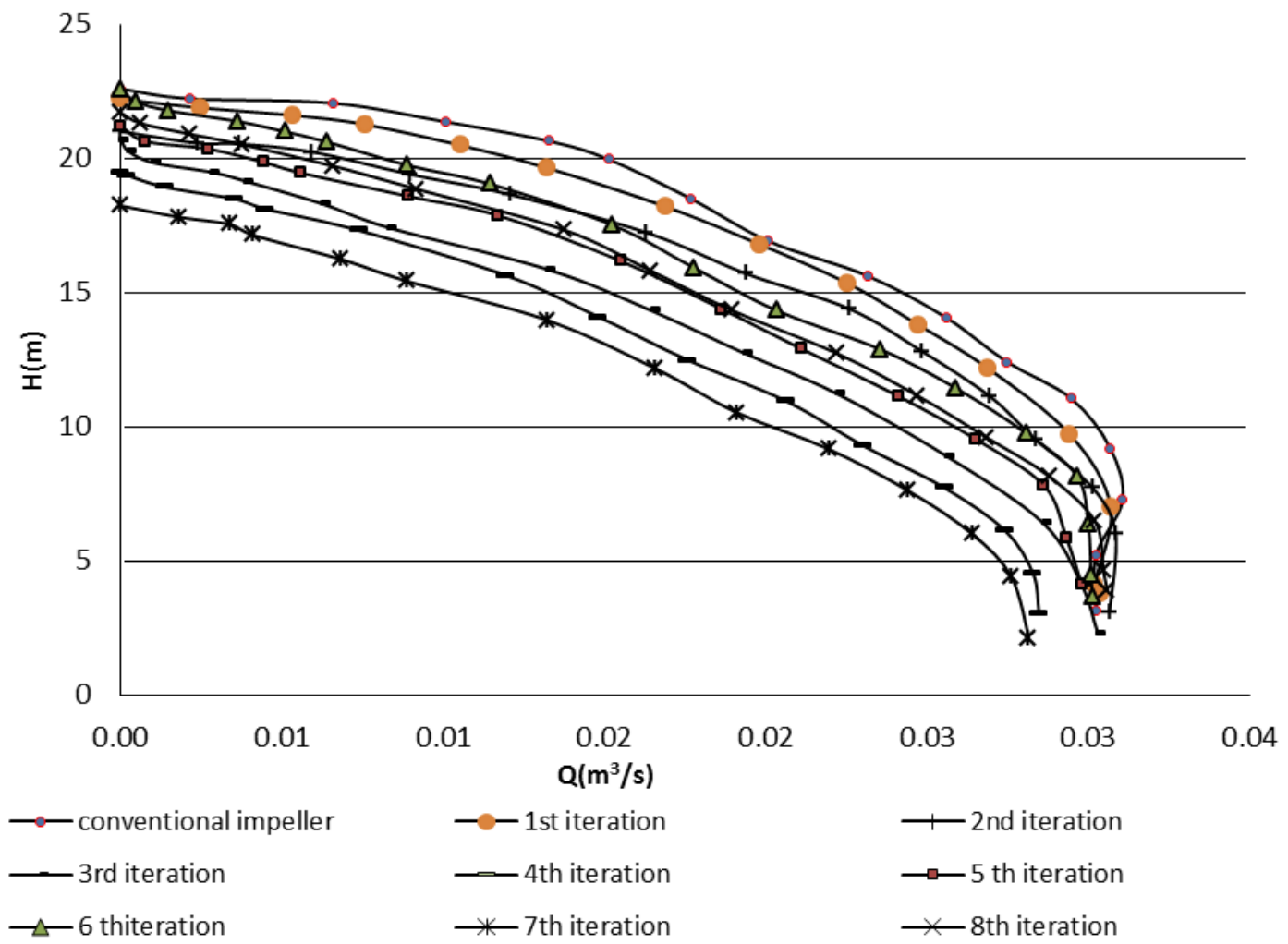

Fig. 4: Variations of the pump head with the pump flow rates for different blade configurations with the conventional impeller at $n=1450 \mathrm{rpm}$.

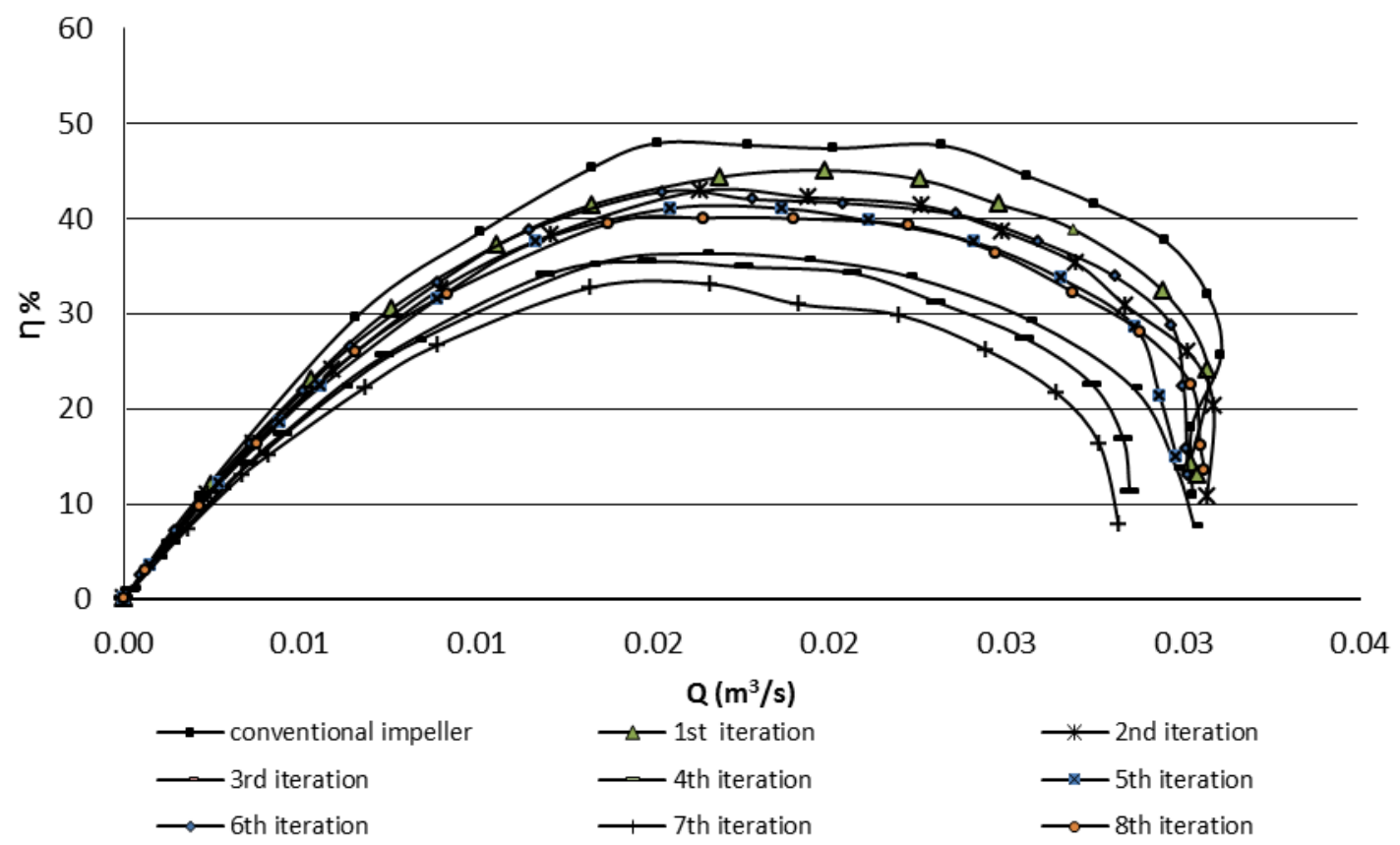

Fig. 5: Variations of the pump efficiency with the pump flow rates for different blade configurations with the conventional impeller at $n=1450 \mathrm{rpm}$. 
For $2^{\text {nd }}$ stage, the head for conventional impeller is higher than the head for $3^{\text {rd }}$ iteration and $4^{\text {th }}$ iteration and the head for $3^{\text {rd }}$ iteration is higher than the head for $4^{\text {th }}$ iteration, the pump efficiency for conventional impeller is higher than the efficiency for $3^{\text {rd }}$ iteration and $4^{\text {th }}$ iteration and the efficiency for $3^{\text {rd }}$ iteration is higher than the efficiency for $4^{\text {th }}$ iteration. The pump head and efficiency are not improved with changing the middle part of the blade configuration, but rotating it counter clockwise has better effect than rotating clockwise [2].

For $3^{\text {rd }}$ stage, the head for conventional impeller is higher than the head for $5^{\text {th }}$ iteration and $6^{\text {th }}$ iteration and the head for $5^{\text {th }}$ iteration is higher than the head for $6^{\text {th }}$ iteration. While in Figure 3.6, the results showed that the pump efficiency for conventional impeller is better than the efficiency for $5^{\text {th }}$ iteration and $6^{\text {th }}$ iteration and the efficiency for $6^{\text {th }}$ iteration is higher than the efficiency for $5^{\text {th }}$ iteration, [11]. The pump head and efficiency are not improved with changing the outer part of the blade configuration, but rotating it clockwise has better effect than rotating counter clockwise.

For $4^{\text {th }}$ stage, the head for conventional impeller is higher than the head for $7^{\text {th }}$ iteration and $8^{\text {th }}$ iteration and the head for $8^{\text {th }}$ iteration is higher than the head for $7^{\text {th }}$ iteration, the pump efficiency for conventional impeller is higher than the efficiency for $7^{\text {th }}$ iteration and $8^{\text {th }}$ iteration and the efficiency for $8^{\text {th }}$ iteration is higher than the efficiency for $7^{\text {th }}$ iteration. The pump head and efficiency are not improved with changing the middle and outer parts of the blade configuration, but rotating it counter clockwise has better effect than rotating counter clockwise.

From Previous results it is clear that, the pump head and efficiency for conventional impeller is higher than the other blade configuration and the $1^{\text {st }}$ iteration is the best configuration of blade to give the best performance of the four stages.

Figure 6 shows the variation of pump maximum efficiency at constant rotational speed of $\mathrm{n}=1450 \mathrm{rpm}$ for different blade configuration which indicates that, $1^{\text {st }}$ iteration is the best blade configuration for the pump maximum efficiency and $7^{\text {th }}$ iteration is the worst blade configuration including the effect of rotating the impeller parts, the worst results for the rotating the midsection part either clockwise or counter clockwise.

Figure 7 shows the variation of the pump design flow rate at constant rotational speed of $\mathrm{n}=1450 \mathrm{rpm}$ for different blade configuration which indicated that, $1^{\text {st }}$ iteration is the best blade configuration for the pump design flow rate and $4^{\text {th }}$ iteration is the worst blade configuration. The difference between the conventional pump efficiency and that for different impeller configurations have been tabulated in Table 2 while the difference between the conventional pump design flow rate and that for different impeller configurations have been tabulated in Table 3.

\subsection{Effect of Impeller Configuration and Speed on the Pump Performance.}

The experimental results (pump efficiency and design flow rate) for different configurations at different rotational speed are plotted in Figures 8 to 15.

Figure 8 shows the effect of $1^{\text {st }}$ iteration and $2^{\text {nd }}$ iteration on the pump maximum efficiency compared with the effect of conventional impeller which indicated that for rotational speed more than $\mathrm{n}=1000 \mathrm{rpm}$, the conventional impeller efficiency is better than that from $1^{\text {st }}$ and $2^{\text {nd }}$ iterations while for rotational speed less than $n=1000 \mathrm{rpm}, 1^{\text {st }}$ and $2^{\text {nd }}$ iterations efficiency is better than that from the conventional one. Below pump rotational speed of $n=1000 \mathrm{rpm}$, the $2^{\text {nd }}$ iteration efficiency is higher than the $1^{\text {st }}$ iteration. 


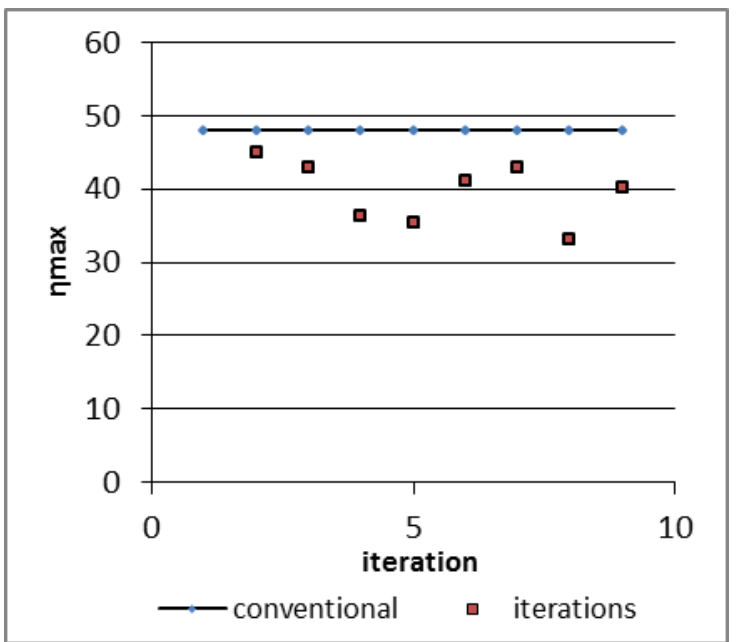

Fig. 6 Variation of pump maximum efficiency for different blade configurations at rotational speed $\mathrm{n}=1450 \mathrm{rpm}$

Table 2: Difference between conventional pump efficiency and that for different impeller configurations at rotational speed $\mathrm{n}=1450 \mathrm{rpm}$

\begin{tabular}{c|c}
\hline \hline Iterations & $\begin{array}{c}\text { Difference from } \\
\text { conventional of } \eta_{\max }(\%)\end{array}$ \\
\hline 1 & 0.94 \\
\hline 2 & 0.90 \\
\hline 3 & 0.76 \\
\hline 4 & 0.74 \\
\hline 5 & 0.86 \\
\hline 6 & 0.89 \\
\hline 7 & 0.69 \\
\hline 8 & 0.84 \\
\hline
\end{tabular}

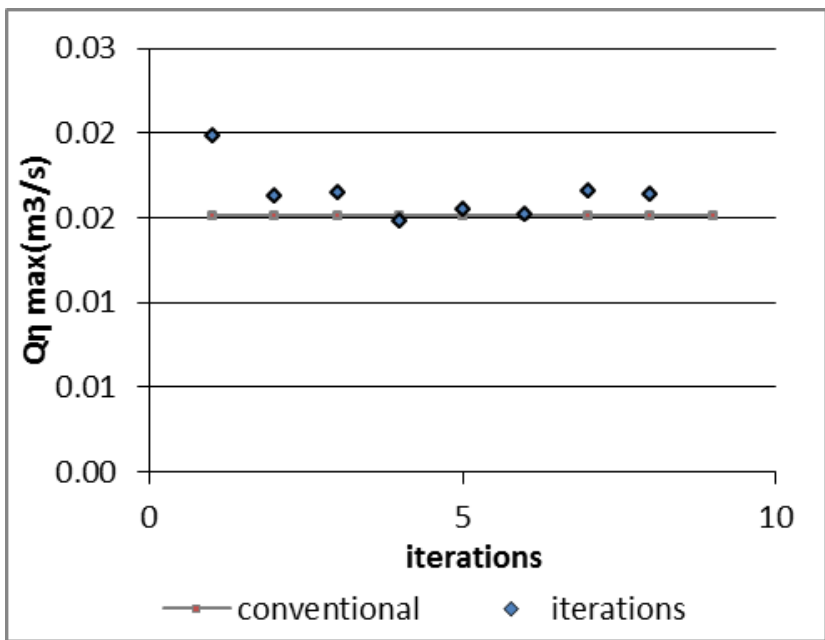

Fig. 7 Variation of pump flow rate at maximum efficiency for different blade configurations at rotational speed $\mathrm{n}=1450 \mathrm{rpm}$

Table 3: Difference between pump flow rate at conventional maximum efficiency and that for different impeller configurations at rotational speed $n=1450 \mathrm{rpm}$

\begin{tabular}{c|c}
\hline Iterations & $\begin{array}{c}\text { Difference from } \\
\text { conventional of } \mathrm{Q}_{\max }(\%)\end{array}$ \\
\hline 1 & 131.13 \\
\hline 2 & 107.95 \\
\hline 3 & 109.27 \\
\hline 4 & 98.01 \\
\hline 5 & 102.66 \\
\hline 6 & 100.66 \\
\hline 7 & 109.93 \\
\hline 8 & 108.61 \\
\hline \hline
\end{tabular}

Figure 9 shows the variation of pump design flow rate for conventional impeller compared with $1^{\text {st }}$ and $2^{\text {nd }}$ iterations at different rotational pump speed which indicated that the pump design flow rate for the $2^{\text {nd }}$ iteration is higher than the pump design flow rate for conventional impeller and $1^{\text {st }}$ iteration for rotational speed up to $n=1300 \mathrm{rpm}$. For rotational speed higher than $1300 \mathrm{rpm}$, the $1^{\text {st }}$ iteration has a pump design flow rate is higher than the two other configurations.

Figure 10 shows the effect of $3^{\text {rd }}$ iteration and $4^{\text {th }}$ iteration on the pump efficiency compared with the effect of conventional impeller which indicated that the conventional impeller is more effective for pump efficiency which increases with increasing of rotational speed. The effect of $3^{\text {rd }}$ iteration and 4 th iteration are all most the same for different rotational speed. 
While in Figure 11, the variation of pump design flow rate for conventional impeller compared with $3^{\text {rd }}$ iteration and $4^{\text {th }}$ iteration at variable rotational speed, the pump design flow rate for conventional impeller at rotational speed ranged from $1000 \mathrm{rpm}$ to $1400 \mathrm{rpm}$ is higher than that for $3^{\text {rd }}$ and $4^{\text {th }}$ iterations. For rotational speed below $1000 \mathrm{rpm}$ and higher than 1400 rpm the pump design flow rate for the $3^{\text {rd }}$ iteration is better than that for conventional impeller and $4^{\text {th }}$ iteration.

Figure 12 shows the effect of $5^{\text {th }}$ iteration and $6^{\text {th }}$ iteration on the pump efficiency compared with the effect of conventional impeller which indicated that the conventional impeller is effective on the pump efficiency specially with increasing the rotational speed and the effect of $5^{\text {th }}$ and $6^{\text {th }}$ iteration is all most the same but at $700 \mathrm{rpm}$ rotational speed the $6^{\text {th }}$ iteration is more effective than the conventional impeller and the $5^{\text {th }}$ iteration.

While in Fig. 13, the variation of pump design flow rate for conventional impeller compared with $5^{\text {th }}$ iteration and $6^{\text {th }}$ iteration at variable rotational speed which indicated that the pump design flow rate for the conventional impeller at rotational speed from $800 \mathrm{rpm}$ to $1400 \mathrm{rpm}$ is higher than the flow rate for $5^{\text {th }}$ and $6^{\text {th }}$ iteration. For rotational speed below $800 \mathrm{rpm}$ and more than $1400 \mathrm{rpm}$ the flow rate for the $5^{\text {th }}$ iteration is better than the flow rate for conventional impeller and $6^{\text {th }}$ iteration,[12].

Figure 14 shows the effect of $7^{\text {th }}$ iteration and $8^{\text {th }}$ iteration on the pump efficiency compared with the effect of conventional impeller which indicated that the conventional impeller is more effective on the pump efficiency than the $7^{\text {th }}$ iteration and $8^{\text {th }}$ iteration while the $8^{\text {th }}$ iteration is more effective than that of the $7^{\text {th }}$ iteration for the same range.

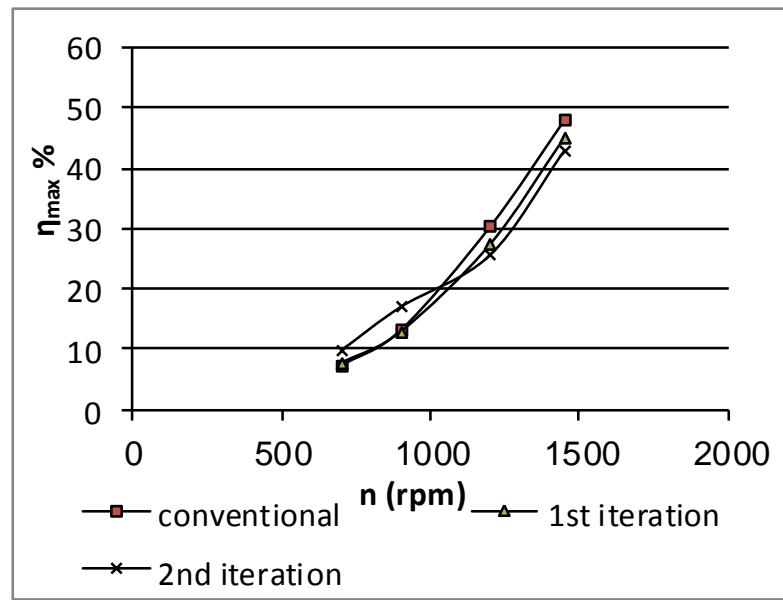

Fig. 8 Pump maximum efficiency for $1^{\text {st }}$ and $2^{\text {nd }}$ iterations, and the conventional one at different rotational pump speeds

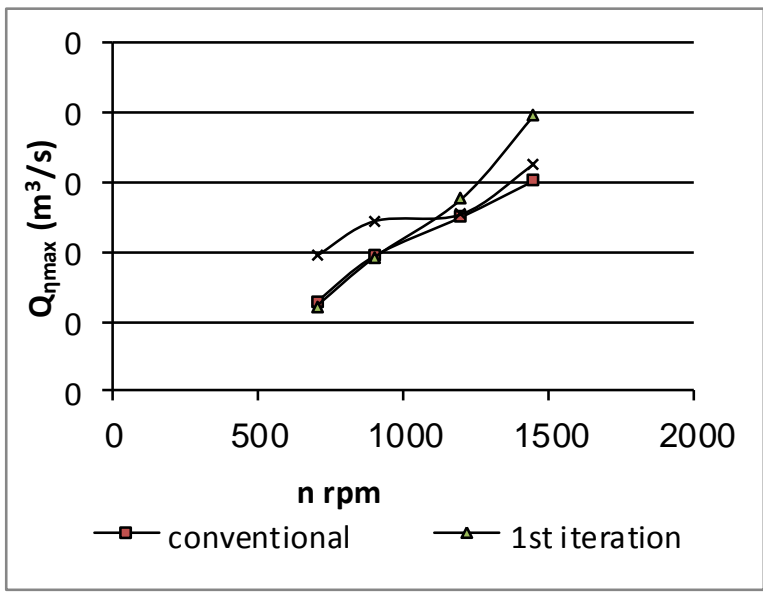

Fig. 9 Pump flow rate $1^{\text {st }}$ and $2^{\text {nd }}$ iterations, and the conventional one at different rotational pump speeds 
Figure 15 shows the variation of pump design flow rate for conventional impeller compared with $7^{\text {th }}$ iteration and $8^{\text {th }}$ iteration at variable rotational speed which indicated that the pump design flow rate for the conventional impeller at rotational speed from $800 \mathrm{rpm}$ to $1400 \mathrm{rpm}$ is higher than the flow rate for $7^{\text {th }}$ and $8^{\text {th }}$ iteration and flow rate for $8^{\text {th }}$ iteration is higher than the flow rate for $7^{\text {th }}$ iteration. For rotational below $800 \mathrm{rpm}$ and more than $1400 \mathrm{rpm}$ the flow rate for the $7^{\text {th }}$ iteration is better than the flow rate for conventional impeller and $8^{\text {th }}$ iteration.

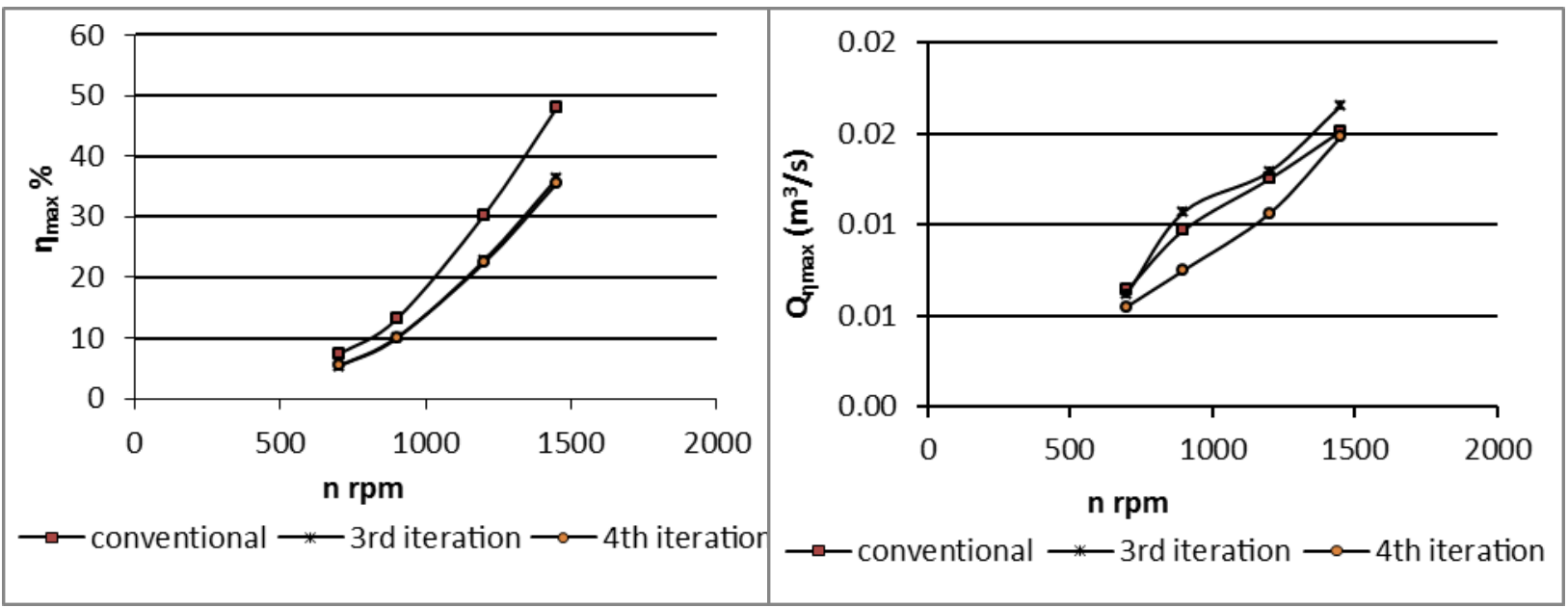

Fig. 10 Pump maximum efficiency for $3^{\text {rd }}$ and $4^{\text {th }}$ iterations, and the conventional one at different rotational speeds
Fig. 11 Pump design flow rate $3^{\text {rd }}$ and $4^{\text {th }}$ iterations, and the conventional one at different pump rotational speeds

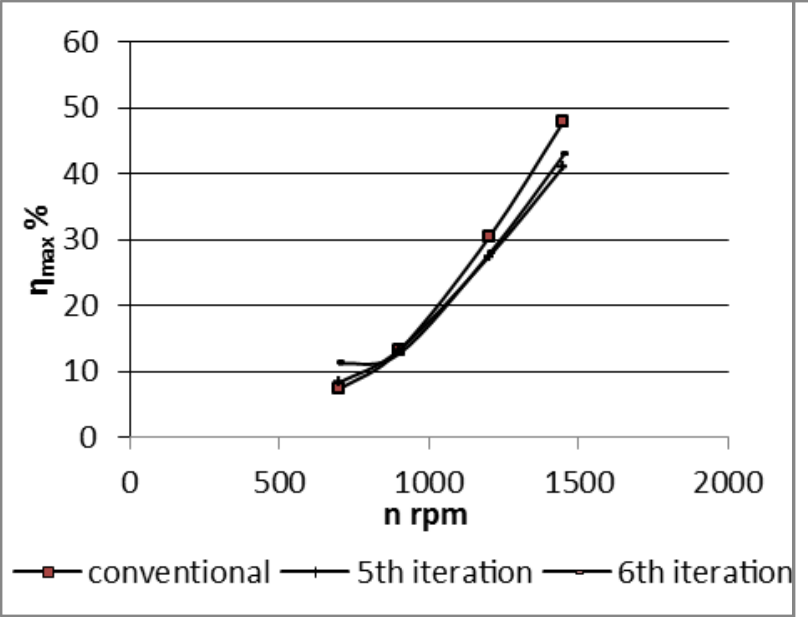

Fig. 12: Pump maximum efficiency for $5^{\text {th }}$ and $6^{\text {th }}$ iterations, and the conventional one at different rotational pump speeds

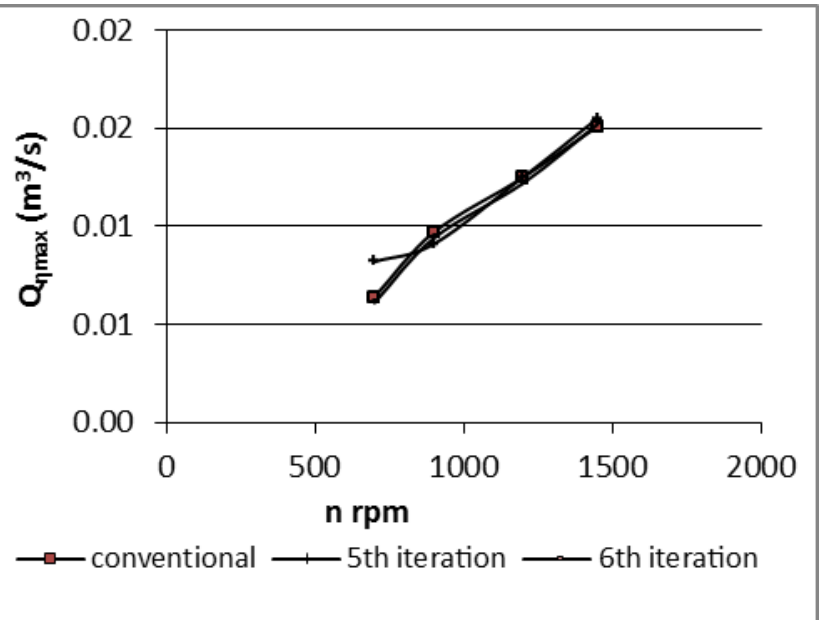

Fig. 13: Pump design flow rate $5^{\text {th }}$ and $6^{\text {th }}$ iterations, and the conventional one at different rotational speeds 


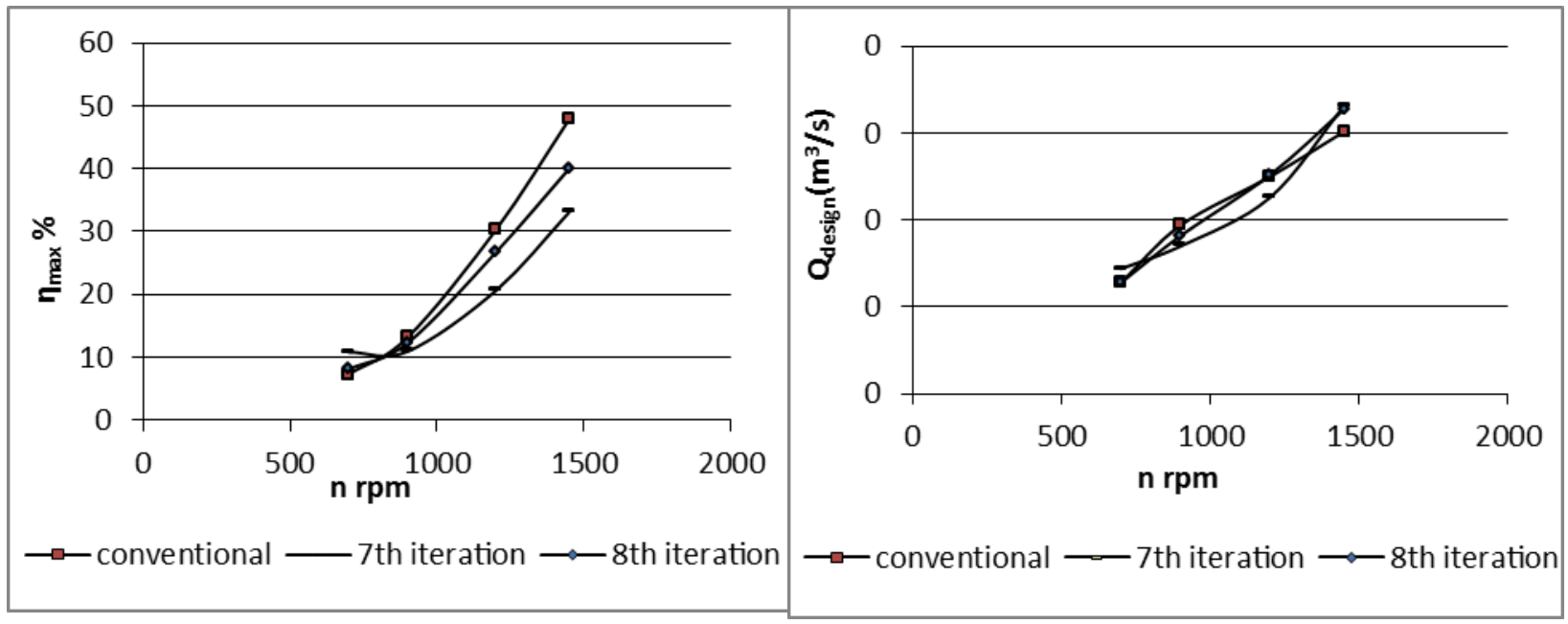

Fig. 14: Pump maximum efficiency for $7^{\text {th }}$ and $8^{\text {th }}$ iterations, the conventional one at different rotational speeds
Fig. 15 Pump design flow rate at $7^{\text {th }}$ and

$8^{\text {th }}$ iterations, the conventional one at different rotational speeds

\section{Conclusion}

In the present paper, design and manufacture of a centrifugal pump equipped with different rotation parts to be easy to change the impeller blade configurations has been introduced. The different arrangement of the pump impeller allows measuring the pump performance at different rotational speed in addition to different impeller blade configurations. An experimental investigation has been made to study the effect of blade's configuration at different rotational speed on the performance of the centrifugal pump.

The experimental pump performance had been measured at different rotational speeds (700 rpm, $900 \mathrm{rpm}, 1200 \mathrm{rpm}, 1450 \mathrm{rpm})$ for four stages of blade's configuration $\left(1^{\text {st }}, 2^{\text {nd }}\right.$, $\left.3^{\text {rd }}, 4^{\text {th }}\right)$ stage.

The pump maximum efficiency for pump rotational speed from $700 \mathrm{rpm}$ to $1000 \mathrm{rpm}$ at rotating the middle and outer part as one unit $24^{\circ}$ counter clockwise ( $2^{\text {nd }}$ iteration). For pump rotational speed more than $1000 \mathrm{rpm}$, the pump maximum efficiency at conventional impeller.

The maximum flow rate at maximum efficiency for pump rotational speed from $700 \mathrm{rpm}$ to $1100 \mathrm{rpm}$ at rotating the middle and outer part as one unit $24^{\circ}$ counter clockwise $\left(2^{\text {nd }}\right.$ iteration). For pump rotational speed more than $1100 \mathrm{rpm}$, the maximum flow rate at pump maximum efficiency at rotating the middle and outer part as one unit $24^{\circ}$ clockwise ( $1^{\text {st }}$ iteration).

The pump design head at rotational speed from $700 \mathrm{rpm}$ to $800 \mathrm{rpm}$ at rotating the middle and outer part as one unit $24^{\circ}$ clockwise $\left(1^{\text {st }}\right.$ iteration). For pump rotational speed from $800 \mathrm{rpm}$ to $900 \mathrm{rpm}$, the pump design head at rotating the middle and outer part as one unit $24^{\circ}$ counter clockwise $\left(2^{\text {nd }}\right.$ iteration), while for pump rotational speed more than $900 \mathrm{rpm}$, the pump design head at conventional impeller.

Rotating the middle and outer part as one unit $24^{\circ}$ counter clockwise $\left(2^{\text {nd }}\right.$ iteration) or $24^{\circ}$ clockwise $\left(1^{\text {st }}\right.$ iteration) $\left[1^{\text {st }}\right.$ stage] gives better effect on the pump performance at low pump rotational speed. 


\section{References}

[1] Gui, L., Gu, C., Chang, H., "Influences of Splitter Blades on the Centrifugal Fan Performances," ASME paper 89-GT-33, ,1989.

[2] Yuan Shouqi, He Youshi, Yuan Jianping, Cong Xiaoqing, Zhao Binjuan, "PIV Measurements and Numerical Simulations of Flow in Centrifugal Pump Impellers with Splitting Vanes," Chinese Journal of Mechanical Engineering, 2006-05

[3] Chen Songshan, Zhou Zhengfu, Ge Qiang, Geng Weiming, Wen Jianlong, Luo Tiqian, "PIV Measurement of Internal Flow in Centrifugal Pump Impeller with Splitters,". Transactions of the Chinese Society for Agricultural Machinery, 2007-02.

[4] ASME FEDSM'00, "Study on Pump Impeller with Splitter Blades Designed by3-D Inverse Design Method,"ASME Fluids Engineering Division Summer Meeting June 1115, Boston, Massachusetts FEDSM2000-11073, 2000.

[5] M. S. E.Hussien, A. H. Lotfy, H. M. Abdalla, I. Saleh, (2001), "Optimum Slot Size and Location in a Radial Vane Impeller for Better Centrifugal Pump Performance", 9th International Conference on Aerospace Sciences \& Aviation Technology, Cairo, Egypt, pp. FD-07.

[6] Kikuyama K., Murakami M., Asakura E., Osuka I, and Liu J., "Velocity Distributions in The Impeller Passages of Centrifugal Pumps: Effects of Outlet Edge Shape of The Impeller Blades on The Pump Performance," Bulletin of JSME, Vol. 28, No. 243, pp. 1963-1969, 1985.

[7] S. Rajendran and Dr. K. Purushothaman, "Analysis of a Centrifugal Pump Impeller using ANSYS-CFX," International Journal of Engineering Research \& Technology (IJERT) Vol. 1 Issue 3, May- 2012, ISSN: 2278-0181.

[8] E. C. Bacharoudis, A.E. Filios, M. D. Mentzos1 and D. P. Margaris1, "Parametric Study of a Centrifugal Pump. Impeller by Varying the Outlet Blade Angle," The Open Mechanical Engineering Journal, 2008, 2, 75-83.

[9] Ulrik Ullum, Jennifer Wright, Oguz Dayi, Ali Ecder, Azzeddine Soulaimani, Robert Piché, and Hemant Kamath, "Prediction of Rotating Stall within an Impeller of a Centrifugal Pump Based on Spectral Analysis of Pressure and Velocity Data," Institute of Physics Publishing Journal of Physics: Conference Series 52 (2006) 36-45 doi:10.1088/1742-6596/52/1/004.

[10] S. I. Chernyshenko. "Non-Linear Development of Rotating Stall in an Axial Compressor at a Near-Critical Flow Rate," Journal of Applied Mathematics and Mechanics. vol. 63, no. 3, pp. 439-447,1999.

[11] A. Fatsis, A. Panoutsopoulou, N.Vlachakis, "Numerical Modeling of a Turbocharger Splitter-Vaned Centrifugal Impeller at off-Design Conditions Part II: Computation of Forces and Torques," Jordan Journal of Mechanical and Industrial Engineering, Volume 4, Number 6, December 2010 ISSN 1995-6665.

[12] Liu Houlin, Wang Yong, Yuan Shouqi, Tan Minggao, and Wang Kai, "Effects of Blade Number on Characteristics of Centrifugal Pumps," Chinese Journal of Mechanical Engineering Vol. 23, 2010.

[13] Sujoy Chakraborty, K.M. Pandey, Bidesh Roy, "Numerical Analysis on Effects of Blade Number Variations on Performance of Centrifugal Pumps with Various Rotational Speeds," International Journal of Current Engineering and Technology, Vol.2, No.1 (March 2012). 